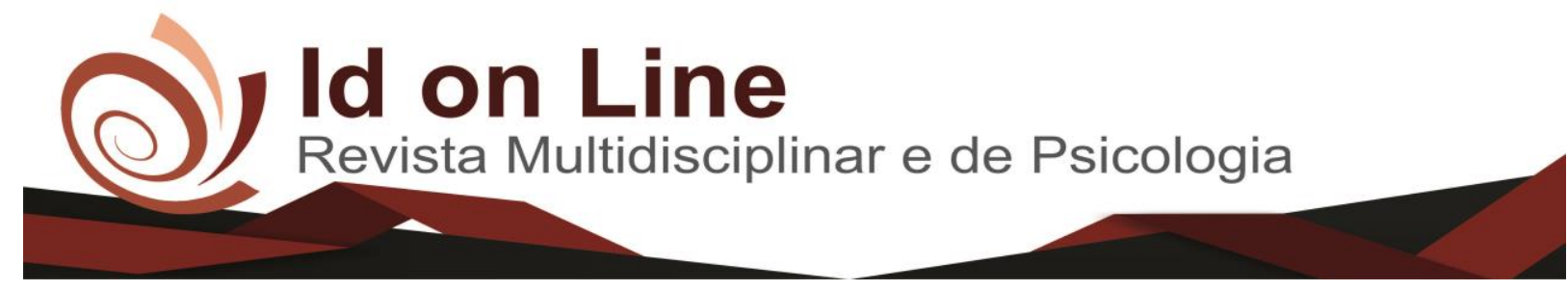

Comment

\title{
Aspectos da Agressividade Infantil: Origem e Desenvolvimento
}

Maria Das Graças Castello Branco Chinelate ${ }^{\text {; Judith Filgueiras Rodrigues }}{ }^{2}$

\begin{abstract}
Resumo: O desenvolvimento desse estudo apresentará os esboços de Ariès (2006) a fim de confirmar se a infância ou o sentimento de infância é considerado historicamente um fenômeno. E, este por sua vez é identificado a gênese e o desenvolvimento desse sentimento. Trata-se de uma revisão integrativa sobre a agressividade infantil. Percebeu-se ser a agressividade um comportamento que preocupa as pessoas que convivem com as crianças que apresentam tal comportamento. Concluiu-se também que os pais, de maneira consciente ou inconsciente, acabam contribuindo para que essa agressividade se desenvolva. É necessário que um adulto procure o apoio de um profissional psicopedagogo, que ajude com relação a questões relacionadas aos limites.
\end{abstract}

Palavras-chave: agressividade infantil. desenvolvimento. raiva.

\section{Child Aggression Aspects: Origin and Development}

\begin{abstract}
The development of this study will present the sketches of Ariès (2006) in order to confirm if the childhood or the feeling of childhood is historically considered a phenomenon. And, this in turn is identified the genesis and the development of that feeling. This is an integrative review on child aggression. It was perceived that aggressiveness is a behavior that worries people who live with children who exhibit such behavior. It was also concluded that parents, consciously or unconsciously, end up contributing to this aggressiveness. It is necessary for an adult to seek the support of a psychopedagogical professional who helps with issues related to limits.
\end{abstract}

Keywords: Children aggressiveness. development. rage.

\section{Introdução}

As crianças na sociedade dos Sec XII ao XVII que eram consideradas como miniaturas de adultos, e por isso teria que ter características adultas até mesmo em vestimentas (ARIÈS, 2006). O autor apresenta sua pesquisa em varias diversas registros, pode-se ser citado a iconografia religiosa e leiga, os diários e dossiês familiares, em cartas, em fim em todos os escritos que apresentava a infância para a sociedade naquele período.

\footnotetext{
${ }^{1}$ Graduação em Ciências Biológicas pela Universidade Iguaçu e em Pedagogia pela Universidade Anhanguera - Uniderp. Especialização em Tutoria à Distância pela Faculdade do Grupo UNIASSELVI. Mestrado em Ciências da Educação pela Universidad San Carlos;

2 Programa de Pós Graduação em Ciências da Educação da Universidad San Carlos, PY.
} 
Observa Áries (2006) a palavra enfant (criança), na língua francesa até o sec. XVIII não apresentava nenhum termo que diferenciasse a infância, da adolescência e da juventude, porque nesses período o que diferenciava era a questão econômica e não a questão biológico, isso é, a dependência econômica era o que distinguia o conceito da infância sendo que esse período acabava ao se sair da dependência dos pais .

No entanto o reconhecimento do critério de dependência econômica para caracterizar a infância em detrimento do critério biológico estabeleceu que o adulto fosse a pessoa que não dependia de seus pais mesmo sendo mais jovem que outra pessoa dependente economicamente de seus pais. Esta segunda seria considerada criança. Não existindo termos para a divisão das idades entre crianças, adolescentes e jovens, mostra que não havia a percepção da evolução da criança nessa fase da vida.

Conforme salienta Ariès (2006), no séc. XIII, a sociedade as crianças eram ignoradas enquanto amostra artística, já que nas pinturas e em retratos nunca eram incluídas, eles eram representados com pequenos homens, ou homens em tamanhos reduzidos. Isso sempre acontecia porque nas pinturas as características físicas apresentada era de um homem pequeno.

Afirma Ariès (2006) que, progressivamente, as crianças foram sendo incluídas nas manifestações artísticas e no século XVI já existia representação das crianças junto à sua família, com seus companheiros de jogos, no meio da multidão no colo da mãe ou segurado pela mão, assistindo aos milagres ou aos martírios.

Isso significa que a sociedade da época passou a olhar a criança de um modo diferente passando a ser considerada engraçadinha e começa a merecer mais atenção. Sendo que a própria família educava as crianças, na qual geralmente com isso despertava um novo sentimento por seus familiares. Ariès apresenta esse período como a gênese do sentimento de infância, no qual estava dividido em duas fases: mais conhecidas a paparicação e o apego.

Sendo que a paparicação deveria ser um anseio acordado pela ingenuidade, beleza, e graciosidade das crianças, com a finalidade que os adultos seja uma formas de aproximação dos adultos para com as crianças, principalmente entre pais e filhos. Assim, as crianças uma espécie de distração para os adultos, pois os gracejos das crianças eram apresentados aos adultos que rodeiam a sua família, muitas vezes eram considerados bichinhos de estimação. Para manter a criança com graça e beleza, são usadas varias medidas, a fim de que não sai do padrão. Com isso a higiene foi melhorada, e os pais apresenta uma preocupação maior com a saúde dos 
pequenos, para que os mesmos não aceitassem perder seus filhos com naturalidade como acontecia até então.

Para Ariès (2006) já apego é um sentimento que surge no séc. XVII, foi considerado uma revelação da sociedade versus a paparicação de uma criança. Ela apresenta separar a criança do adulto a fim de educá-la na disciplina e nos costumes, vale salientar que tudo deve estar dentro de uma visão mais racional. É relevante ressaltar que foi dentro de uma conservadora e moralista que as crianças foram educadas.

Diante desse cenário, apresentaram a obrigação da determinação de normas e regras para a criança a sua educação e formação que tinha a preocupação de atender a necessidade daquela época. É por isso, que a criança precisa ser alvo de influência familiares e de seu grupo social.

De acordo com Ariès (2006) o surgimento desse novo homem contribuiu para o aparecimento das primeiras instituições educacionais contribuindo para que os adultos compreendessem a particularidade da infância e a importância tanto moral como social e metódica das crianças em instituições especiais, adaptadas a essas finalidades.

Apenas na Idade Moderna que se consegue uma evolução nas relações sociais da criança, pois nesse momento ela passa a ter um papel central nas famílias e na sociedade, e a partir dessa percepção os laços afetivos das famílias são fortalecidos entre as crianças e os adultos, ou entre filhos e pais. Pois, é a partir desse momento que a criança é vista no coletivo, a família nesse momento tem uma forte preocupação com o seu bem estar e o seu desenvolvimento intelectual, já que tais fatores são fatores indispensáveis para a alteração de relação social entre as crianças e os adultos.

Train (1997) apresenta, no entanto, que nas relações sociais surge a criança agressiva e há grupos de especialistas de vida que acreditam que todas as ações são determinadas pelas experiências de vida. A criança agressiva é agressiva por causa de sua experiência de vida e de sua criação.

Estes especialistas são os behavioristas, eles acreditam que os seres humanos agem sempre conforme seus interesses, sendo assim possível modelá-los mantendo controle sobre seu comportamento. Desta forma, quando se deseja que uma criança se comporte de uma maneira determinada, basta que seja forçado tal comportamento recompensando-a pelo feito e, se a criança comporta-se mal, é necessário ignorar tal comportamento para extingui-lo.

Segundo os estudos behavioristas, a criança é agressiva porque sempre que agir desta 
forma recebe a atenção do grupo de seu convívio e então é recompensada por seus atos. Se esta recebesse atenção somente quando não tivesse sendo agressiva, tornar-se-ia mais sociável.

De acordo com Train (1997) para os behavioristas os acontecimentos de agressões devem ser considerados procedidos frustrados, pois acontece quando a criança almeja a realização de alguma coisa, e por algum causa não conseguiria realizar, reagiria de maneira agressiva verbalmente ou ate mesmo física. Vale salientar, que essa situação é a causadora de ansiedade incontrolável.

É preciso ressaltar que também existem aquelas crianças que apresentam diversas frustrações, e sempre buscando um mundo de fantasias. Essa crianças apresenta um tipo de agressividade que é bastante comum entre elas e também tolerada pela na sociedade em que se vive, já que é um mundo que não representar nenhuma ameaça a ninguém, mas vale salientar que essa situação pode levar a criança à automutilação ou até mesmo a um suicídio (Ibid).

Na cultura atual, a auto-agressividade existe como traço normal, desde que se mantendo em certos limites; ela permite ao homem a análise de suas próprias atitudes e a crítica das mesmas; um indivíduo sem força auto-agressiva seria incapaz de autocrítica.

Como mostra os estudos feitos por Train (1997) os behavioristas acreditam que é necessário o indivíduo passar pela frustração para buscar realizações na vida, sendo capaz a qualquer indivíduo tolerar a dor da frustração. Na criança, a intensidade da agressividade é relacionada não somente com o nível de frustração, mas, também com a percepção que ela tem de injustiça ou de rejeição.

Já os psicanalistas acreditam que o caráter do indivíduo é a junção entre sua personalidade singular e a soma dos resultados de suas experiências no mundo. Seguindo esta linha de pensamento, obtém-se a análise de que o indivíduo nasce com certas qualidades, porém suas vivências podem gerar deficiências como a teimosia, e ou, a meticulosidade. Isto ocorre porque, desde o início da vida, a criança interage com o meio, vivendo infinitas experiências boas e ruins. Nelas existem duas tendências - uma inata para o amor e outra para a destruição - as quais podem variar, dependendo da criança e das experiências vividas (Ibid).

De acordo, com França e Yaegashi(2005) as crianças desde bebê apresentam algum comportamento agressivo, pois a criança geralmente tem algumas reações agressicas, pode-se destacar reclamar, exigir, bater os pés ou gritar, entre oures. Já Ferreira e Wiezzel(2008) afirmam que a agressividade pode causar fortes danos, físicos, morais e psicológicos, apresenta ainda que a não é um traço da personalidade, mais sim um ato que se manifesta. 
Para Marcelli (1998) apresenta que por volta de dois ou três anos essa situação de agressividade pode manifestar-se por meio de atos agressivos aos pais, aos irmãos aos amigos, entre outros, apresentando com isso comportamentos incomuns, se destaca alguns puxar os cabelos, arranhar e morder as crianças com a sua mesma idade entre outros. Vale salientar, que a partir dos quatro anos, a criança apresenta uma agressão verbal, sendo que nesse períodos a agressividades dos meninos são maiores que as meninas.

Aos cinco anos a agressividade transforma-se em hostilidade, manifestando-se sob forma de oposição sistemática ao meio, denunciando assim, suas perturbações afetivas. Este é um sinal evidente de alerta aos pais e professores em primeira instância - o primeiro sinal claro é a negativação na evolução natural do desenvolvimento da criança.

Sabe-se que é pela força agressiva que a criança alcança o equilíbrio perdido em contato com o ambiente, e de tal maneira se firma, encontrando o seu lugar. Mas, se a agressividade é reprimida, a criança condicionará e transferirá a turbulência em comportamentos vistos como anti-sociais. Se não lhe for impostos limites, mais tarde não temerá a autoridade dos pais e professores, adquirirá sentimentos de poder e os enfrentará de forma aberta e hostil, se opondo a todos e ao meio em que vive.

Nesse sentido Marcelli (1998) apresenta que as ações agressivas ao longo dos anos a tendência é de ir desaparecendo. Sendo possa apresentar casos que essa agressividade possa perdurar por mais tempo do que o devido. Podendo ainda existir atitudes agressivas, gritando e batendo nos colegas de sua idade e nos adultos, entre outras ações. Vale salientar que tais atitudes agressivas geram comportamentos associais e anti-sociais ligadas de forma direta a uma série de problemas futuros.

\section{Sentimento de ameaça}

Quando a imagem do indivíduo sofre qualquer tipo de ameaça ele reagirá utilizando mecanismos sutis e técnicas sofisticadas para proteger sua auto-imagem.

Se o indivíduo possuir uma imagem forte de si mesma, tendo definido quem é e que papel desempenha no mundo de forma clara e precisa, será então capaz de resistir ao ataque; porém se a auto-imagem deste indivíduo for fraca, ele interpretará muitas ações e intenções 
como uma ameaça e reagirá no meio de forma agressiva, fazendo o uso de técnicas para a sua autodefesa.

Como aponta Train (1997) há três tipos de técnicas. São elas:

- Contra-atacará com agressividade verbal ou sarcasmo;

- Distorcerá as informações para atender a suas próprias propostas;

- Fugirá daquilo que não deseja ouvir.

A criança constitui um indivíduo particularmente vulnerável, e justamente por ser pequena, reage mais fácil e rapidamente de forma defensiva àquilo que lhe oferece qualquer tipo de ameaça a sua imagem, a seu mundo. Por isso, é comum a criança evitar situações que lhe representem ameaça, se recusando a ir à escola, e ou, a outras instituições. O perigo está na repressão do seu próprio sentimento, pois, ela passará a evitar se expressar no intuito de defender seu mundo tal como o conhece.

Para fugir dos problemas é comum as crianças se refugiarem num mundo de fantasias ou apatia, podendo agir de forma aparentemente bizarra - sem vínculos que possam ser percebidas. Mas, na verdade cada criança possui características próprias de sua personalidade, e a agressividade lhe acrescenta um grau particularmente alto de sensibilidade, o que vem explicar suas reações de autodefesa.

\section{Sentimentos de raiva}

Outra dimensão de agressividade na infância é aquela movida à raiva. Esta atitude não é necessária à sobrevivência, por isto ela requer uma maior atenção. $\mathrm{Na}$ agressividade movida à raiva, está-se num estado de mobilização emocional; em casos extremos, a recompensa pela agressividade poderá ser a própria dor que se inflige a outra pessoa.

Train (1997) considera que esse comportamento altamente agressivo busca vivenciar o sentimento da sua própria existência, podendo ser reforçado pelo seu grupo de convívio através de suas reações frente ao seu comportamento.

A criança agressiva associa a situação de ferir alguém com a experiência prazerosa de interação social, podendo ser este seu único veículo de contato com os outros. Este caso requer atenção por ser extremamente difícil de lidar. Entre outras, Train (1997) destaca três reações agressivas que motivam tais crises. 
- Sentimento de frustração;

- Sentimento de injustiça, negligência ou descuido a si próprio;

- Dificuldades de enfrentar críticas de si próprio e de seus amigos.

$\mathrm{Na}$ incapacidade de se expressar de forma aceitável, a criança frustrada reagirá numa cólera de raiva. O que esta criança precisa, é aprender a negociar e a expressar de forma clara seus pensamentos, facilitando assim o seu convívio com o meio.

Oaklander (1980, p 232) textualmente afirma que muitas vezes uma criança é dita como agressiva, ao manifestar um momento de raiva, que geralmente são momentos passageiros, sendo que esses momentos devem ser considerados como desvios de sentimentos.

\section{Crianças insociáveis}

Cardoso (1996) descreve que o principal propósito na infância, nas suas interações, é o desejo de brincar, serem amigas e trocarem experiências. Porém, as crianças agressivas possuem ao contrário, o desejo de controlar todos os brinquedos e brincadeiras desenvolvidas em grupo, são inquietas, barulhentas, só se comunicam em gritos, choronas, exigem em demasia a atenção do adulto. Estas crianças são do contra, negativas, chatas, dominadoras e possessivas, mandonas, enfim, suas presenças nem sempre vão ser bem vindas.

Nos termos de Oaklander (1980), o autor afirma que as atitudes agressivas, são considerados ações anti-sociais, pois compreendem que na sua maioria esse comportamentos torna-se destrutivos. É relevante ressaltar que uma criança agressiva possivelmente possua sentimentos negativos profundos, por exemplo, sentimento de ira, sentimento de rejeição, insegurança e ansiedade, sentimentos de mágoa. E com isso percebe-se que essa criança deverá ter medo de revelar-se os seus reais sentimentos, pois acredita que se o fizer perderá a sua característica. Por esse motivo é tal criança apresenta esses comportamentos apenas como um método de de sobrevivência.

Uma boa tentativa para controlar comportamentos como esses, é estar buscando estabelecer regras e objetivos para ambas as partes, fazer valê-las e, também, assegurar que a criança não interprete como crítica tudo o que você diz. 


\section{Crises e birras}

Na visão de Asha (2005), este tipo de comportamento é naturalmente aceitável e não requer muita preocupação naquelas crianças menores de cinco anos, pois faz parte de um estágio do seu desenvolvimento. Ela caminha em direção a conquista da melhor forma de se comunicar e negociar suas necessidades e anseios.

Quando esta fase persiste além da idade cronológica (cinco anos) e o tempo dispensado a esta criança, requer uma maior atenção, é a hora em que pais e professores devem se manter em alerta. Apresenta "necessidades especiais" por representar um perigo para si e para os outros; passa a destruir seus pertences e do meio, torna-se dominadora, desobediente, mentirosa e briguenta.

O que esta criança precisa é de limites e reconhecer que as demais pessoas ao seu redor, também têm necessidades e anseios próprios.

\section{Agressividade nos meninos e nas meninas}

A agressividade aparece em diferentes níveis entre meninos e meninas, porém, essa característica é acentuada no menino a partir do seu segundo ano de vida. Está ligada a vários fatores tais como: padrão biológico, a cobrança excessiva pela sociedade ao estabelecer o estereótipo masculino do "macho" (o que por si só, já é uma agressividade); sem contar as definições culturais dos papéis atribuídos aos homens e as mulheres.

Pode-se notar, no entanto, que devido à emancipação feminina este fator tende a diminuir relativamente.

Ballone $(2008)^{1}$ afirma que as diversificas conduta entre as crianças apresentam principalmente na idade escolar, pois é o período em que a criança inicia o processo de socialização. Sendo que os meninos se encontra menos preparados psicologicamente que as meninas. Sendo que essas ter maiores problemas para a socialização ou a vida em grupo.

\footnotetext{
${ }^{1}$ <www.psiqweb.med.br> 


\section{Níveis de agressividade}

Os níveis de agressividade variam. Já se considerou a preponderância dos fatores genéticos, já se considerou a preponderância do meio, mas hoje se sabe que é a junção desses fatores que faz com que uma criança seja agressiva ou não. Se ela está acostumada a receber carinho e a conviver com pessoas não agressivas, a probabilidade de se tornar agressiva é menor. Por outro lado, se a criança cresce em um ambiente hostil, na maioria dos casos vão desenvolver um instinto agressivo. Mas há caso de crianças que tem uma natureza passiva e, mesmo vivendo num ambiente hostil, tornam-se cada vez mais acuadas. Ou ainda crianças que mesmo criadas em um ambiente de muito afeto se tornam agressivas.

Há também os níveis de agressividade patológicos, em que a influência do meio, ncluindo aí os filmes violentos, vídeo-games, a mídia com os noticiários que passam na televisão, rádios, jornais, internet, se associam a uma característica já existente. O papel da televisão, aliás, é justamente como o da família e o da escola - exerce grande importância na formação do indivíduo.

De forma geral as eventuais explosões de raiva não devem ser vistas como comportamentos problemáticos. De qualquer maneira é importante que os pais e demais profissionais da educação se mantenham atentos se a agressividade é ansiosa. Nestas horas, é sempre bom tentar separar a agressividade dos próprios adultos, que costumam projetá-las nas crianças. O principal ingrediente nesta difícil tarefa é buscar sempre o diálogo e oferecer limites à criança.

Asha (2005) defende que a questão do limite tem muito a ver com a agressividade. As crianças que não tem limites tendem a se tornar agressivas quando estes lhe são impostos, e na relação entre pais e filhos, há sempre uma luta pelo poder; se a criança encontrar espaço para exercitar esta agressividade, ela utilizará este espaço. Daí a importância de estar estabelecendo limites, tanto em casa como na escola.

Infelizmente, na maioria dos casos as mães são as grandes culpadas da agressividade infantil, quando, por exemplo, não dão deveres aos filhos, nem responsabilidades, nem limites. Ao superprotegerem os filhos, fazem com que estes se tornem pessoas sem nenhuma tolerância à frustração. Talvez as mães confundam o papel materno com a permissividade extrema em busca da simpatia de seus filhos. Ballone (2008) explica que "outras vezes pretendem, com essa absoluta falta de limites para seus filhos serem tidas por moderninhas e joviais". 
Ballone (2008) afirma ainda que, geralmente mães de crianças agressivas tendem a atribuir mais hostilidades às condutas de seus filhos, qualificando negativamente traços de sua personalidade e ressaltando sua má conduta.

Ballone (2008) ressalta que o grupo familiar é a primeiro grupo social que a criança tem oportunidade de ter aprendizado emocional, será a partir dela criança poderá aprender a relação consigo, a relação com meio, e por fim a relação com os seus sentimentos. Este aprendizado representa a soma do que as crianças ouvem e vêem os pais fazendo, mas também, e principalmente aprenderam com os modelos que seus responsáveis oferecem, quando estes lidam com seus próprios sentimentos.

Para que a criança se desenvolva dentro de um padrão normal, isto é, sem grandes problemas, é necessário que ela cresça em um ambiente onde sejam satisfeitas as suas necessidades psicológicas fundamentais de: independência, segurança, afeto, aceitação, respeito e consistência.

Na ótica de França (2000) se essas necessidades psicológicas fundamentais não forem satisfeitas pelo meio familiar da criança, as atitudes patológicas familiares podem causar reflexos no desenvolvimento da personalidade infantil. Essa conduta patológica impede o desenvolvimento normal da personalidade da criança e sua auto-realização.

É normal no desenvolvimento da criança passar pela fase em que reagir com agressividade e hostilidade ao meio é a forma de estar garantindo que seus desejos e sentimentos sejam plenamente realizados. Já na infância, a criança sofre um certo grau de ansiedade e teme a frustração, mas ambas, quando vividas de forma satisfatória estará preparando a mesma para melhor estar suportando este problema que ocorrerá por toda a vida e, só tende a auxiliar no crescimento e amadurecimento de qualquer indivíduo.

Mas as atividades escolares apresenta uma forte influência no processo de formação. Sendo que caberá ao educador reger 0a criança a fim de evitar as condutas agressivas que são condenadas na sociedade em geral, a fim de proporcionar oportunidades para exercer tais atividades agressiva. É necessária apresentar atitudes nas quais são aceitas pela sociedade. Ajudando com isso a criança modelar a sua condição limitando a apresentar suas emoções e criatividade, de maneira ajustada de acordo coma a sociedade.

Percebe-se que a agressividade é um comportamento que preocupa as pessoas que convivem com as crianças que apresentam tal comportamento. Conclui-se também que os pais, de maneira consciente ou inconsciente, acabam contribuindo para que essa agressividade se 
desenvolva. A agressividade já é manifestada em bebês, quando, por exemplo, sentem prazer ou desprazer frente a situações impostas. Conforme as crianças vão crescendo, este comportamento pode ou não desaparecer.

Para minimizar os comportamentos agressivos, é necessário que um adulto procure o apoio de um profissional psicopedagogo, que ajude com relação a questões relacionadas aos limites. Isso deve acontecer principalmente quando os pais não estejam sendo assertivos na disciplina junto aos seus filhos, e esses por sua vez, apresentarem atitudes agressivas e/ou condutas antissociais.

\section{Referências}

ASHA - American Speech-Language-Hearing Association. (Central) Auditory Processing Disorders. Rockville: ASHA, 2005.

ARIÈS, Phillipe. História social da criança e da família. Tradução Dora Flaksman. Rio de Janeiro: LTC, 2006.

BALLONE, G.J. Violência e Agressão da criança do adolescente e do jovem.[S.1], 2002. PsiqWeb Psiquiatria Geral. Disponível em: <www.psiqweb.med.br〉. Acesso em: 20 mar. 2008.

CARDOSO, Ofélia Boisson. Problemas da infância. São Paulo: Melhoramentos, 1996.

FRANÇA, T. S. X. Socialização da pessoa com deficiência adquirida,o processo, os personagens e as máscaras. João Pessoa: Idéia,2000.

MARCELLI, D. Manual de psicopatologia da infância de Ajuriaguerra. 5. ed. Porto Alegre: Artmed, 1998.

OAKLANDER, V. Descobrindo crianças: a abordagem gestáltica com crianças e adolescentes. 11. ed. São Paulo: Summus, 1980.

TRAIN, Alan. Ajudando a Criança Agressiva. 3. ed. São Paulo: Papirus, 1997.

Como citar este artigo (Formato ABNT):

CHINELATE, Maria das Graças C.B.; RODRIGUES, Judith F. Aspectos da Agressividade Infantil: Origem e Desenvolvimento. Id on Line Revista Multidisciplinar e de Psicologia, 2017, vol.11, n.38, p.212-222. ISSN: 1981-1179. 